\title{
Corporate Universities' Configuration in the Italian Context: An Exploratory Study
}

\author{
Alessia Sammarra ${ }^{1}$, Sara Mormino ${ }^{2,3}$, Laura Innocenti ${ }^{2} \&$ Silvia Profili ${ }^{4}$ \\ ${ }^{1}$ Department of Industrial and Information Engineering and Economics, University of L'Aquila, L'Aquila, Italy \\ ${ }^{2}$ People Management Competence Centre \& Lab, LUISS Business School, Rome, Italy \\ ${ }^{3}$ Department of Human Sciences, LUMSA University, Rome, Italy \\ ${ }^{4}$ European University of Rome, Rome, Italy \\ Correspondence: Alessia Sammarra, Department of Industrial and Information Engineering and Economics, \\ University of L'Aquila, Via Giuseppe Mezzanotte - Località Acquasanta - 67100 L'Aquila, Italy. E-mail: \\ alessia.sammarra@univaq.it
}

Received: September 30, 2017

doi:10.5539/ijbm.v12n12p97
Accepted: November 1, $2017 \quad$ Online Published: November 20, 2017

URL: https://doi.org/10.5539/ijbm.v12n12p97

\begin{abstract}
The popularity of Corporate Universities (CUs) has grown considerably over the last decades, gaining both scholars and practitioners' interest. This exploratory study contributes to the CU-related research field adding empirical evidence to the scant literature that examines how the $\mathrm{CU}$ configuration is operationalized in the Italian context. Our findings reveal that different features exist with varied prominence among the selected CUs, revealing a great heterogeneity that cannot be explained uniquely by their stage of life cycle. Nevertheless, it is worth noting some common features across the selected cases. First of all, these CUs devote most of their activities exclusively or prominently to their internal audiences. Moreover, although they have relationships with universities and business schools, the level of involvement of external partners is still modest. Together these two aspects denote a low level of openness of these entities that may be explained by institutional and cultural factors characterizing the Italian context.
\end{abstract}

Keywords: corporate universities, knowledge management, organizational configuration, training and development.

\section{Introduction}

The popularity of Corporate Universities (CUs) has grown considerably over the last decades (Meister, 1998). In a recent report, Boston Consulting Group estimated that, in the United States, the number of CUs doubled between 1997 and 2007, from 1,000 to 2,000, while worldwide the number of companies with formal CUs reached 4,000 units (Kolo, Strack, Cavat, Torres, \& Bhalla, 2013).

A key task for both scholars and practitioners has been to understand the $\mathrm{CU}$ rising phenomenon. This attempt has been so far problematic because CUs vary to a great extent from organization to organization. Several authors argue that this is partly due to the fact that existing CUs may fall in different stages of their life cycle. According to Lui Abel and Li (2012), as any other organization, the CUs life cycle model reveals different stages of development: (i) start-up, (ii) growth, and (iii) maturity (Greiner, 1972; Quinn \& Cameron, 1983), each of them characterized by different processes, infrastructures and capabilities. While CUs in the start-up phase are just starting their operations and processes, in the growth stage they have already in place well-documented standards. Finally, in the maturity stage, CUs are experts with external industry recognition.

Although CUs may vary significantly according to their stage of development, several authors claim that CUs have idiosyncratic features that make them a distinct phenomenon. Therefore, much of the discussion to date has focused on the development of configurations that identify the CUs features and highlight how they differ from other related phenomena and, notably, from traditional corporate training departments/functions (Allen, 2002; Rademakers, 2005; Lui Abel \& Li, 2012).

This approach is certainly crucial to advance knowledge on CUs as ordering, classification, or other grouping of the objects or phenomena under investigation represent fundamental tasks for promoting theoretical 
advancement in any scientific field (Carper \& Snizek, 1980).

CUs configurations can be discovered empirically, gathering data and processing this evidence using quantitative analysis (taxonomies) or via theoretical reasoning using a priori knowledge (typologies). Both methodologies have shortcomings: taxonomies tend to be specific and may lack broader applicability to other settings and organizations (Samuel \& Mannheim, 1970), while pure typologies may be "largely the product of rather personal insight [and] may not accurately reflect reality" (Hambrick, 1984: p. 28). These considerations highlight the importance of evaluating CUs configurations developed either theoretically or empirically against the reality of the phenomenon under investigation. As a matter of fact, a recent review of the literature (Lui Abel \& $\mathrm{Li}, 2012$ ) reveals a lack of empirical evidence on real CUs configurations. As Lui Abel \& Li (2012) remarked, empirical studies on CUs mostly examined one or two aspects in isolation such as: learning strategies and governance of CU (e.g., Rademakers, 2005; Rivera \& Paradise, 2006), the evaluation methods (e.g., Allen, 2002; Bober \& Bartlett, 2004; Guerci, Bartezzaghi, \& Solari, 2010); internal or external partnerships (e.g., Blass, 2005; Thompson, 2000); ICT adoption (e.g. Iannotta, Gatti, \& D'Ascenzo, 2016). However, a true configuration approach should require considering the $\mathrm{CU}$ as a complex entity characterized by the interaction of many features that mutually influence each other. Lui Abel and Li's empirical study (2012) is one of the few systemic investigations that adopted an integrative approach on a large sample of CUs. However, as the study was based on a North American sample, results may have limited implications for CUs based in other countries. The other few empirical studies that adopt a comprehensive approach to $\mathrm{CU}$ configurations use a single or a few case studies (e.g., Baldwin, Danielson, \& Wiggenhorn, 1997; El-Tannir, 2002; Jansink, Kwakman, \& Streumer, 2005; Shaw, 2005; Holland \& Pyman, 2006). Unfortunately, among them, the inclusion of cases of Italian CUs is only few exception.

To date, there is a lack of empirical evidence on the configuration of CUs in the Italian context, and most of the available data are provided in practice-oriented reports (Fondazione Campus, 2013; ASFOR, 2015; Nomisma, 2016) that often lack theoretical or conceptual underpinning. In order to fill this gap, we conducted an exploratory study using a multiple case study design to address the following questions:

1) To what extent CUs in the Italian context embody the distinctive features identified in the taxonomies/typologies proposed in the extant literature?

2) How does the configuration of Italian CUs differ according to their stage of development?

This study makes two key contributions to the extant literature on CUs. First, it contributes to research on CUs configuration by enlarging the scope of empirical studies that adopt an integrative approach. Indeed, our aim is to shed light on the interaction of the several distinctive features of CUs rather than concentrating on one or two factors in isolation. Second, this study is a first attempt to investigate how the CU configuration in the Italian context reflects the features of taxonomies/typologies proposed in the literature.

In the following sections we will first introduce the concept of Corporate University to better understand its configuration and underline its strategic role in modern organizations in promoting training and development processes and the overall organizational performance and success. We will then analyze the empirical results of an exploratory study that highlights differences and similarities in the Corporate Universities' configurations in the Italian context. Finally, we will discuss our findings and introduce avenues for future research.

\section{Distinctive Features of CUs: A Conceptual Framework}

According to Meister (1998, p. 29), CUs can be defined as "the strategic umbrella for developing and educating employees, customers and suppliers in order to meet an organization's business strategies". This definition suggests that "such organizations exist in diverse forms, operate under a wide range of titles and undertake a broad spectrum of education, training and development activities" (Prince \& Beaver, 2001; p.18). According to Lui Abel and Li (2012) two main features characterize CUs. First, they are engaged in the development of organizationally specific skills. Central to the training approach of CUs is that knowledge transfer will help the firm's development only if the training content is applicable and suited for the specific characteristics of the organizational context. This approach cannot be fulfilled from outside the firm by referring to educational agencies and, in general, to the external organization of knowledge (Antonelli, Cappiello, \& Pedrini, 2013) but requires the adoption of an internal faculty. Second, they represent an instrument to link learning programs to organizational goals and business performance. In doing that, CUs' scope goes beyond that of providing training, including also skill building, knowledge production, and change management (Morin \& Renaud, 2004).

Furthermore, CUs play a proactive role, being guided by long term strategic plans in order to support the business objectives of the organization, more than simply responding reactively to specific training needs. 
El Tannir (2002) defines CU as "a function or a department that develops the skills for employees, and integrates them into the strategic orientation of the corporation with strong emphasis on leadership and improved work-related performance" (p.77). To reach these goals, CUs have to incorporate several complex roles, being a change management catalyst, a leadership development agent, and a business development instrument (Andresen \& Irmer, 1999).

A number of authors have proposed useful taxonomies and typologies to describe the roles played by CUs (Fresina, 1997; Prince \& Beaver, 2001).

According to the taxonomy developed by Fresina (1997), Corporate Universities can be distinguished into three prototypes. Each of them focuses on a specific strategic purpose. The first prototype aims at reinforcing and perpetuating current cultures, behaviors and competitiveness; the second type is designed to support and manage strategic change; the third, recognized as the most challenging model, has the purpose to drive and shape the future direction of the organization.

Walton (1999) categorized three generations of Corporate University according to their mission and learning strategy. According to this developmental model, the first generation of CUs is directed to the promotion of organizational culture and values; the focus is on classroom-based activities. The second generation follows a more strategic approach to organizational learning, by pursuing a wider range of activities and often the development of partnerships with other employees or institutions. Finally, the third generation includes CUs that are strategically aimed at developing the organization's intellectual capital through the most effective adoption of technology and the implementation of virtual elements in learning and communicating processes.

Lui Abel and Li (2012) provided an aggregated view of CU characteristics based on a summary of the extant CU literature. The authors identified 13 dimensions that characterize CUs, grouped into 4 profiles (organizational, learning delivery, operational, partnership) according to the similarities of their functions and consistently with the taxonomy proposed by Prince and Stewart (2002). The organizational and partnership profiles capture the strategic nature of CUs while the operational and learning delivery profiles outline the functioning model of these organizations. The four functional profiles are described in Table 1.

Lui Abel and Li's aggregated view (2012) will provide the conceptual framework for this study and inform the qualitative analysis in order to provide a better comprehension of CUs configuration in the Italian context. Consistently with this aggregated view, in this paper we focus on the organizational profile, the learning delivery profile, the operational profile, and the partnership profile to identify the distinctive features of Italian CUs.

Table 1. Conceptual framework: the distinctive features of CUs

\begin{tabular}{|c|c|c|}
\hline Profile & Dimensions & Contents \\
\hline \multirow[t]{5}{*}{$\begin{array}{l}\text { Organizational } \\
\text { profile }\end{array}$} & Strategy and mission & $\begin{array}{l}\text { Identifies the scope of activities (training and development, knowledge management, } \\
\text { change management, strategy implementation) }\end{array}$ \\
\hline & Governance and leadership & Identifies the governance model \\
\hline & Structure & $\begin{array}{l}\text { Defines the arrangement of workflows and authority relationships (centralized versus } \\
\text { decentralized model) }\end{array}$ \\
\hline & Stage of development & $\begin{array}{l}\text { Identifies the life cycle stage (in terms of size, years in existence, processes and } \\
\text { recognition) }\end{array}$ \\
\hline & Evaluation & $\begin{array}{l}\text { Captures the evaluation and measurement model used to assess the CU performance } \\
\text { and impact }\end{array}$ \\
\hline Partnership profile & Partnerships & $\begin{array}{l}\text { Captures the ability of CU to develop internal and external partnership (e.g., with HR } \\
\text { Departments, Business Units, Academia) }\end{array}$ \\
\hline Operational profile & $\begin{array}{l}\text { Financing sources } \\
\text { Technology use }\end{array}$ & $\begin{array}{l}\text { Defines the way } \mathrm{CU} \text { is funded and its financial autonomy } \\
\text { Identifies the use of technology in CU's activities (e.g., the use of learning } \\
\text { management systems) }\end{array}$ \\
\hline Learning delivery & Learner population & Identifies the recipients of CU's activities \\
\hline Profile & Faculty & Defines the nature of CU's faculty (internal and/or external) \\
\hline
\end{tabular}

Source. Lui Abel \& Li (2012, p. 105).

\section{Method}

This study applies a multiple case study design (Yin, 1994) in order to provide a 'thick description' of the 
configurational model of CUs in the Italian context.

In accordance with qualitative methods, our sampling strategy was aimed at selecting a theoretical rather than a probability sample. First, we identified target cases using the following selection criteria:

1) the naming "Corporate University" or "Corporate Academy" was formally adopted by the candidate cases;

2) the candidate cases should include CUs at different stages of development and from several industries.

Then, we involved a panel of experts in order to validate the candidate cases identified in the first stage. This procedure consistently reduces the risk of attribution bias. At the end of this process we selected 9 CUs for inclusion in the present study. A description of the sample is provided in Table 2.

Table 2. Overview of the CUs studied

\begin{tabular}{|c|c|c|c|c|c|c|c|}
\hline & \multicolumn{3}{|c|}{ Corporate } & \multicolumn{4}{|c|}{$C U$} \\
\hline & Industry & Employees & $\begin{array}{c}\text { Turnover } \\
\text { (MLN euro) }\end{array}$ & $\begin{array}{c}\text { Year of } \\
\text { foundation }\end{array}$ & $\begin{array}{l}\text { Life cycle } \\
\text { stage }\end{array}$ & Employees & $\begin{array}{c}\text { Training } \\
\text { hours } \\
\text { delivered per } \\
\text { year }\end{array}$ \\
\hline Case 1 & Food \& Beverage & 1,500 & 220 & 2015 & Start-up & 2 & 3,500 \\
\hline Case 2 & $\begin{array}{c}\text { Business Process } \\
\text { Outsourcing }\end{array}$ & 9,108 & 244 & 2014 & Start-up & 2 & \\
\hline Case 3 & $\begin{array}{c}\text { Mail, Logistics, } \\
\text { Insurance \& Financial } \\
\text { Services }\end{array}$ & 142,000 & 30,739 & 2015 & Start-up & 55 & $3,115,000$ \\
\hline Case 4 & TLC & 44,171 & 13,796 & 2015 & Growth & 70 & $1,340,000$ \\
\hline Case 5 & Bank \& Insurance & 2,000 & 120 & 2010 & Growth & 8 & 39,000 \\
\hline Case 6 & Bank \& Insurance & 25,731 & 5,215 & 2012 & Growth & 19 & $1,000,000$ \\
\hline Case 7 & Food \& Beverage & 33,219 & 9,542 & 2000 & Maturity & 14 & 67,800 \\
\hline Case 8 & Energy & 73,000 & 75,658 & 2007 & Maturity & & $2,519,000$ \\
\hline Case 9 & Aviation & 4,236 & 849 & 2005 & Maturity & 41 & 68,000 \\
\hline
\end{tabular}

To increase the reliability of results, we decided to use triangulation of data sources and methods. An on-line survey addressed to the Head of the selected CUs was designed to collect detailed data from each case regarding the following aspects: (i) CU business context and demographics; (ii) CU governance, structure and stage of development; (iii) CU operational processes; (iv) CU internal and external partnerships. Data collection also included seven qualitative interviews with managers of the sampled organizations and documentary analysis to gain in-depth knowledge of the internal and external factors that affected the process of establishment and evolution of the CU. Table 3 provides information regarding the key informants involved in qualitative interviews.

Table 3. Key informants involved in qualitative interviews

\begin{tabular}{ll}
\hline Interviewees' role & Organization \\
\hline Head of Corporate University & Case 3 \\
Head of Development, Compensation and Change Management & Case 3 \\
Head of Education and Communication & Case 4 \\
Head of Knowledge Management and Training & Case 6 \\
Head of HR Development & Case 8 \\
Head of Corporate University & Case 9 \\
\hline
\end{tabular}

\section{Results and Discussion}

Results are presented in Tables 4-7, that describe the features of Italian CUs in terms of organizational, operational, partnership and learning profiles. 
Table 4. The organizational profile

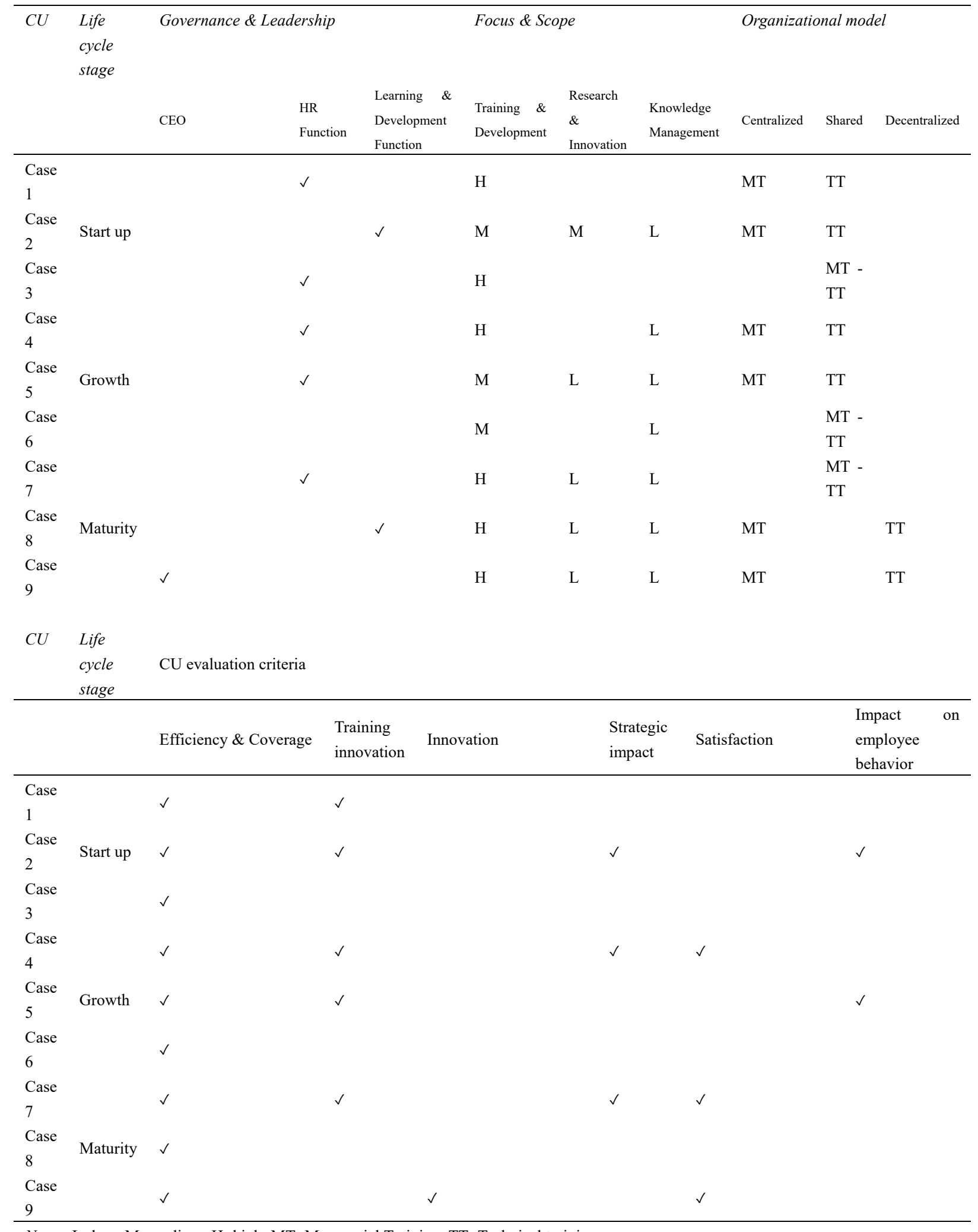

Notes: $\mathrm{L}=$ low; $\mathrm{M}=$ medium; $\mathrm{H}=$ high; $\mathrm{MT}=$ Managerial Training; $\mathrm{TT}=$ Technical training.

We found that one common trait across Italian CUs is that they are all corporate-driven initiatives supported by a corporate budget. According to the literature, CEO involvement is one of the key organizational features of successful CUs as a close connection to top management ensures that the CU is a key strategic vehicle. Yet, 
results show that only in one case CU reports directly to the CEO. Interestingly, this occurs for one of the oldest CU that already entered in the maturity stage. Most CUs report directly to the HR Director, while in a few cases the CU reports to the Learning \& Development unit within the HR Department.

According to Jansink, Kwakman, and Streumer (2005), an important characteristic of CU is the "span of scope". CUs distinguish themselves from traditional training functions because they are involved in a wider array of activities beyond training, which remains very central but is complemented by research and knowledge management. Our results show that the CUs scope is still very focused on training and development activities. Interestingly, mature CUs devote their attention also toward research and innovation programs, while knowledge management is not among the scope of activity of these organizations, regardless of their stage of development.

With regards to organizational structure, several scholars claimed that companies establish CUs in order to systemize the training function, maximize the investments in education, spread common culture and share leadership models. Therefore, CUs are generally expected to adopt a more centralized model, as compared to traditional training departments/functions with respect to coordination and management of all training and learning activities. This should lead to increased efficiency while ensuring effective integration of learning contents across an enterprise (Rivera \& Paradise, 2006). In line with this expectation, we found that a centralized model prevails in most CUs for the coordination of managerial training programs. However, a federated model prevails for technical training, showing that organizations continue to struggle with a pure centralized model. For the delivery of technical training most CUs, including those in the maturity stage, adopt a shared or a decentralized model to reduce conflicts with local offices and difficulties in administering global learning investments.

Among the organizational profile criteria, the evaluation measures adopted to assess the CUs impact represent a crucial dimension to identify proper CUs from traditional training functions. As previously stated, a distinctive trait of CUs is the strong connection between organizational strategy and learning activities. For this reason CUs should be measured mainly on their ability to link the educational goals to the strategic needs of the organization. However, results show that the use of efficiency and coverage criteria is still prevalent on that of innovation and strategic criteria.

Table 5. The operational profile

\begin{tabular}{|c|c|c|c|c|c|}
\hline \multirow[t]{2}{*}{$C U$} & \multirow[t]{2}{*}{ Life cycle stage } & \multirow[t]{2}{*}{ Financial autonomy } & \multicolumn{3}{|c|}{ Technology use } \\
\hline & & & LMS & LMS management & E-learning adoption \\
\hline Case 1 & & no & & & $\mathrm{L}$ \\
\hline Case 2 & Start up & no & $\checkmark$ & $\mathrm{J}$ & $\mathrm{L}$ \\
\hline Case 3 & & no & $\checkmark$ & A & $\mathrm{L}$ \\
\hline Case 4 & & no & $\checkmark$ & A & $\mathrm{L}$ \\
\hline Case 5 & Growth & no & $\checkmark$ & $\mathrm{J}$ & $\mathrm{L}$ \\
\hline Case 6 & & no & $\checkmark$ & $\mathrm{J}$ & $\mathrm{L}$ \\
\hline Case 7 & & no & $\checkmark$ & A & $\mathrm{L}$ \\
\hline Case 8 & Maturity & no & $\checkmark$ & $\mathrm{J}$ & $\mathrm{L}$ \\
\hline Case 9 & & no & $\checkmark$ & $\mathrm{J}$ & $\mathrm{L}$ \\
\hline
\end{tabular}

Notes: J=joint management with consultancy firms; $\mathrm{A}=$ autonomous management; $\mathrm{L}=$ low level of adoption.

As far as the operational profile is concerned, the use of a blended approach and the focus on active learning methods are often recognized as distinctive features of CUs (Morin \& Rinaud, 2004). According to the literature, CUs are expected to take advantage of technologies, mainly in terms of efficiency and flexibility of learning processes (Homan \& Macpherson, 2005). Walton (1999) distinguished three generations of CUs using e-learning adoption and digitalization as an indicator of the CUs level of sophistication and ability to spread a learning culture. All the CUs involved in our study adopted a Learning Management System. Despite this evidence, findings reveal that most of the CUs' activities mainly occur in traditional classrooms. Only in one case we found a balance between frontal teaching and digital learning (virtual or blended). 
Table 6. The partnership profile

\begin{tabular}{|c|c|c|c|c|c|c|c|}
\hline \multirow[t]{2}{*}{$C U$} & \multirow{2}{*}{$\begin{array}{c}\text { Life cycle } \\
\text { stage }\end{array}$} & \multicolumn{6}{|c|}{ Relationship with University } \\
\hline & & Overall & $\begin{array}{l}\text { Academic } \\
\text { professors } \\
\text { involved in } \\
\text { CU training }\end{array}$ & $\begin{array}{c}\text { Employees } \\
\text { involved in } \\
\text { academic } \\
\text { training }\end{array}$ & $\begin{array}{l}\text { Scientific } \\
\text { Advisory }\end{array}$ & $\begin{array}{c}\text { Joint planning } \\
\text { of training }\end{array}$ & $\begin{array}{l}\text { Certified } \\
\text { programs }\end{array}$ \\
\hline \multicolumn{8}{|l|}{ Case 1} \\
\hline Case 2 & Start up & $\mathrm{L}$ & & & & $\checkmark$ & \\
\hline Case 3 & & M & & & & $\checkmark$ & \\
\hline Case 4 & & M & $\checkmark$ & & $\checkmark$ & $\checkmark$ & $\checkmark$ \\
\hline Case 5 & Growth & M & $\checkmark$ & $\checkmark$ & $\checkmark$ & $\checkmark$ & \\
\hline Case 6 & & M & $\checkmark$ & $\checkmark$ & $\checkmark$ & $\checkmark$ & $\checkmark$ \\
\hline Case 7 & & $\mathrm{~L}$ & & & & & \\
\hline Case 8 & Maturity & M & & & $\checkmark$ & $\checkmark$ & $\checkmark$ \\
\hline Case 9 & & $\mathrm{~L}$ & & $\checkmark$ & & & \\
\hline
\end{tabular}

Notes: $\mathrm{L}=$ low level of involvement; $\mathrm{M}=$ medium level of involvement.

According to the literature, for CUs to be successful it is crucial to develop networks with world-class learning partners, such as Universities and Business Schools (Prince \& Stewart, 2002). We found that partnership with Academia is still underdeveloped among Italian CUs. Although most organizations reported having relations with academic institutions, this collaboration is limited to the involvement of professors in the CU's faculty and the joint planning of training initiatives. No collaboration is mentioned in terms of research projects or knowledge production.

With regards to recipients, a common feature across the selected CUs is that they all devote most of their activities to employees. Only two CUs reported to address programs also to partners and customers, and in one case specific initiatives were devoted to students from schools and universities. Interestingly, none of the nine CUs offered programs to employees' relatives and/or the wider social community.

According to the extant literature, CUs respond to the need for idiosyncratic training that combines codified knowledge with the specificity of the organizational culture and strategic goals. This demand is usually fulfilled through the constitution of an internal faculty. This is also considered a crucial means for CUs to become a vehicle for knowledge-production. As a matter of fact, employees learn and produce knowledge in various ways: seeking new solutions to work problems, dealing with various customer demands, making new products, or implementing new work procedures. The involvement of knowledgeable employees as internal trainers allows spreading and reusing this valuable knowledge. Our findings show that all CUs but one have an established pool of internal trainers. The most frequent approach to identify faculty members is top-down selection through line managers and/or HR nomination based on employees' seniority and level of expertise. Interestingly, CUs in the maturity stage are more likely to adopt formalized policies to manage the internal faculty and have a broader set of criteria to identify faculty members, which include also bottom-up approaches based on self-nomination.

Table 7. The learning delivery profile

\begin{tabular}{|c|c|c|c|c|c|c|c|c|}
\hline \multirow[t]{2}{*}{$C U$} & \multirow[t]{2}{*}{ Life cycle stage } & \multicolumn{3}{|c|}{ Learner Population } & \multicolumn{4}{|c|}{ Internal Faculty } \\
\hline & & Employees & Customers & Partners & $\begin{array}{c}\text { Faculty } \\
(\mathrm{y} / \mathrm{n})\end{array}$ & $\begin{array}{c}\text { Register } \\
(\mathrm{y} / \mathrm{n})\end{array}$ & Policy (y/n) & Selection \\
\hline Case 1 & & $\mathrm{H}$ & & $\mathrm{L}$ & $\checkmark$ & & & \\
\hline Case 2 & Start up & $\mathrm{H}$ & & & & & & \\
\hline Case 3 & & $\mathrm{H}$ & & & $\checkmark$ & & & \\
\hline Case 4 & & $\mathrm{H}$ & & & $\checkmark$ & $\checkmark$ & & \\
\hline Case 5 & Growth & $\mathrm{H}$ & & & $\checkmark$ & & & \\
\hline Case 6 & & $\mathrm{H}$ & & & $\checkmark$ & $\checkmark$ & $\checkmark$ & \\
\hline Case 7 & Maturity & $\mathrm{H}$ & & & $\checkmark$ & $\checkmark$ & $\checkmark$ & Self \\
\hline Case 8 & Avictur iny & $\mathrm{H}$ & & & $\checkmark$ & & & Self \\
\hline
\end{tabular}

Notes: H=high involvement, $\mathrm{ME}=$ medium involvement, $\mathrm{L}=$ low involvement. 


\section{Conclusions}

This exploratory study contributes to the CU-related research field adding empirical evidence to the scant literature that examines how the $\mathrm{CU}$ configuration is operationalized in the Italian context. Our findings reveal that all the selected CUs display several distinctive features proposed in the literature, proving that they go beyond merely calling themselves a corporate university. However, the different features exist with varied prominence among the CUs, revealing a great heterogeneity across the nine cases that cannot be explained uniquely by their stage of life cycle.

Nevertheless, it is worth noting some common features across the selected cases. First of all, these CUs devote most of their activities exclusively or prominently to their internal audiences (employees, professionals and managers). Moreover, although they have relationships with universities and business schools, the level of involvement of external partners is still modest. Together these two aspects denote a low level of openness of these entities. This feature may be explained by institutional and cultural factors, given the traditional distance between academy and industry that characterizes the Italian context.

The only distinctive feature that seems related to the CU life cycle concerns the role of internal faculty. Among the selected CUs, mature entities show a greater commitment to knowledge production through a stronger investment in formal policies to select and engage the internal faculty.

\section{Limitations and Recommendations for Future Research}

This research study has some limitations that pave the way to future research opportunities.

Our work is based on an exploratory study and represents a first stage of a larger research project. Further investigations are required to better understand the Corporate University phenomenon.

A theoretical implication that emerges from the study suggests devoting greater attention in future research to the role of academic and business environments as institutional forces that affect CUs configuration.

Moreover, the results illustrated are limited to nine organizations in the Italian context; future research should investigate, for instance, how CUs' configurations and distinctive features differ across business sectors, types of organizations, and geographical, social and cultural contexts.

Finally, future studies might directly address some key actors involved inside (e.g. employees, managers, internal faculty) and outside the organizations (e.g., partners) in the CUs activities, to investigate their perceptions and experiences and deepen some key dimensions that characterize CUs.

\section{References}

Allen, M. (2002). The corporate university handbook: Designing, managing, and growing a successful program. AMACOM Div American Mgmt Assn.

Andresen, M., \& Irmer, A. (1999). Global Beat: Corporate Univrsities in Germany. The New Corporate University Review, 7(6).

Antonelli, G., Cappiello, G., \& Pedrini, G. (2013). The Corporate University in the European utility industries. Utilities Policy, 25, 33-41. https://doi.org/10.1016/j.jup.2013.02.003

ASFOR (2015). IX Ricerca ASFOR - Trend della Formazione Manageriale. Retrieved from http://www.asfor.it/ricerche/osservatorio-asfor/item/2226-anno-2015. Accessed 01/10/2016

Baldwin, T. T., Danielson, C., \& Wiggenhorn, W. (1997). The evolution of learning strategies in organizations: From employee development to business redefinition. The Academy of Management Executive, 11(4), 47-58.

Blass, E. (2005). The rise and rise of the corporate university. Journal of European Industrial Training, 29(1), 58-74. https://doi.org/10.1108/03090590510576217

Bober, C. F., \& Bartlett, K. R. (2004). The utilization of training program evaluation in corporate universities. Human Resource Development Quarterly, 15(4), 363-383.

Carper, W. B., \& Snizek, W. E. (1980). The nature and types of organizational taxonomies: An overview. Academy of Management Review, 5(1), 65-75.

El-Tannir, A. A. (2002). The corporate university model for continuous learning, training and development. Education + Training, 44(2), 76-81. https://doi.org/10.1108/00400910210419973

Fondazione Campus (2013). 2 Rapporto sul mercato delle Corporate University in Italia. Retrieved from http://www.fondazionecampus.it/fileadmin/documents/CU_InvioElettronico.pdf Accessed 01/10/2016 
Fresina, A. (1997). The three prototypes of corporate universities. Corporate University Review, 5(1), 3-6.

Greiner, L. E. (1972). Evolution and Revolution as Organizations Grow. Harvard Business Review, 50(4), 37-46 1972. Retrieved from https://ssrn.com/abstract $=1504482$

Guerci, M., Bartezzaghi, E., \& Solari, L. (2010). Training evaluation in Italian corporate universities: a stakeholder - based analysis. International Journal of Training and Development, 14(4), 291-308.

Hambrick, D. C. (1984). Taxonomic approaches to studying strategy: Some conceptual and methodological issues. Journal of Management, 10(1), 27-41. https://doi.org/10.1177/014920638401000104

Homan, G., Macpherson, A. (2005). E-learning in the corporate university. Journal of European Industrial Training, 29(1), 75-90. https://doi.org/10.1108/03090590510576226

Holland, P., \& Pyman, A. (2006). Corporate universities: a catalyst for strategic human resource development? Journal of European Industrial Training, 30(1), 19-31. https://doi.org/10.1108/03090590610643851

Iannotta, M., Gatti, M., D'Ascenzo, F. (2016). The Diffusion of ICT Across Italian Corporate Universities: An Exploratory Study. In: D'Ascenzo F., Magni M., Lazazzara A., Za S. (Eds.), Blurring the Boundaries Through Digital Innovation. Lecture Notes in Information Systems and Organisation, (Vol. 19, pp. 37-47). Springer, Cham. https://doi.org/10.1007/978-3-319-38974-5_4

Jansink, F., Kwakman, K., \& Streumer, J. (2005). The knowledge-productive corporate university. Journal of European Industrial Training, 29(1), 40-57. https://doi.org/10.1108/03090590510576208

Kolo, P., Strack, R., Cavat, P., Torres, R., \& Bhalla, V. (2013). Corporate Universities: An Engine for Human Capital. BCG Perspectives, Retrieved July 18, 2013, from http://www.bcgperspectives.com

Lui Abel, A., \& Li, J. (2012). Exploring the corporate university phenomenon: Development and implementation of a comprehensive survey. Human Resource Development Quarterly, 23(1), 103-128. https://doi.org/10.1002/hrdq.21122

Meister, J. C. (1998). Corporate Universities: lessons in building a world-class workforce. New York: McGraw-Hill.

Morin, L., \& Renaud, S. (2004). Participation in corporate university training: its effect on individual job performance. Canadian Journal of Administrative Sciences/Revue Canadienne des Sciences de l'Administration, 21(4), 295-306. https://doi.org/10.1111/j.1936-4490.2004.tb00346.x

Nomisma (2016). Corporate Academy in Emilia-Romagna. Retrieved from http://cmcgruppo.com/cmc/files/2011/09/Rapporto-Nomisma_-Corporate-Academy-in-ER_2016.pdf

Prince, C. \& Beaver, G. (2001), Facilitating organisational change; the role and development of the corporate university. Strategic Change, 10(4), 189-199. https://doi.org/10.1002/jsc.541

Prince, C., \& Stewart, J. (2002). Corporate universities - an analytical framework. Journal of Management Development, 2l(10), 794-811. https://doi.org/10.1108/02621710210448057

Quinn, R. E., \& Cameron, K. (1983). Organizational life cycles and shifting criteria of effectiveness: Some preliminary evidence. Management Science, 29(1), 33-51. https://doi.org/10.1287/mnsc.29.1.33

Rademakers, M. (2005). Corporate universities: driving force of knowledge innovation. Journal of Workplace Learning, 17(1/2), 130-136. https://doi.org/10.1108/13665620510574513

Rivera, R. J., \& Paradise, A. (2006). State of the Industry in Leading Enterprises: ASTD's Annual Review of Trends in Workplace learning and performance. American Society for Training \& Development, Alexandria, VA.

Samuel, Y., \& Mannheim, B. F. (1970). A multidimensional approach toward a typology of bureaucracy. Administrative Science Quarterly, 15(2), 216-228. http://www.jstor.org/stable/2391492

Shaw, S. (2005). The corporate university: global or local phenomenon? Journal of European Industrial Training, 29(1), 21-39. https://doi.org/10.1108/03090590510576190

Thompson, G. (2000). Unfulfilled prophecy: The evolution of corporate colleges. Journal of Higher Education, 71(3), 322-341. http://dx.doi.org/10.1080/00221546.2000.11780825

Walton, J. (1999). Strategic Human Resource Development. London: Pitman.

Yin, R. (1994). Case study research: Design and methods (2nd ed., 1st ed., 1984). Thousand Oaks, CA: Sage Publications. 


\section{Copyrights}

Copyright for this article is retained by the author(s), with first publication rights granted to the journal.

This is an open-access article distributed under the terms and conditions of the Creative Commons Attribution license (http://creativecommons.org/licenses/by/4.0/). 